\title{
Estimated Brain Volume at Term Age in Very Preterm Infants with Uncomplicated Grade II And III Intraventricular Haemorrhage
} Ehab Sorour ${ }^{1}$, Hossam Ibrahim ${ }^{2}$

\author{
${ }^{1}$ Pediatric Department, ${ }^{2}$ Radiology Department, Faculty of Medicine, Alazhar University \\ Corresponding author: Ehab Ibrahim Sorour, Mobile (+20)01013309288, E-mail: ehabsorour@yahoo.com
}

\begin{abstract}
Background and aims: In very pre-term new-borns, cerebral lesions are usually complicated with neuro-developmental issues. But un-complicated intra-ventricular haemorrhage (IVH) has no reliable associations with poor outcomes.

Objective: In the current work we aimed to assess the impact of un-complicated brain haemorrhage on assessed brain size at term-equivalent ages (TEA), through standard indices made from cranial ultrasound (cUS).

Methods: This study included 87 very pre-term babies [<32 weeks' gestational age (GA)] up to and at TEA which were divided into two groups; group one included infants with uncomplicated grades II or III IVH, and group two included infants with normal cUS. A previously described standards based on linear measurements were used to calculate the estimated brain volumes at TEA and to compare between the two groups using independent groups t-test; p-value $\leq 0.05$ was considered significant.

Results: 19 very pre-term babies with un-complicated IVH and 68 with normal images have been studied. Bi-parietal diameter at TEA was shorter in the IVH new-borns (72 vs $87 \mathrm{~mm}$, p-value < 0.05 ) while thalamo-occipital distance was longer in IVH infants $(23.7 / 21.4 \mathrm{~mm}$, p-value $<0.05))$. But, there were non-significant changes at TEA for bi-frontal diameter (69.3 vs $70.1 \mathrm{~mm})$, transverse cerebellar diameter $(51.1$ vs $49.9 \mathrm{~mm})$, valued cranial size $\left(384 / 414 \mathrm{cc}^{3}\right)$, valued cerebral size $\left(338 / 341 \mathrm{cc}^{3}\right)$ and Levene's ventricular index $(1.38 / 1.23 \mathrm{~cm})$.

Conclusions: There is no difference in assessed cerebral size at TEA, built on measures performed at the bedside via cranial US among very pre-term new-borns with dependably ordinary images and those with un-complicated grade II and grade III IVH.
\end{abstract}

Keywords: Cranial ultrasound, Pre-term, Intraventricular haemorrhage.

\section{INTRODUCTION}

Parents and health workers dealing with very preterm newborns are highly concerned for the significant danger of neuro-developmental difficulties. The dangers of this problem differ inversely with gestational ages (GA), but other clinical variables and biomarkers are as well very significant ${ }^{\mathbf{1}}$.

The danger of long-term neuro-developmental impairments connected to perinatal brain injuries and changed brain maturations in pre-term babies is considerably high ${ }^{2}$. The best method and timing of neuroimaging for recognising elevated-risk babies is under argument ${ }^{3}$. Early and consecutive cUS may be satisfactory utilized to diagnose main brain injuries; however, it is not sensitive as MRI for the more common diffuse white matter injuries complicating pre-term delivery. cUS still the commonest utilized neuroimaging method for pre-term babies as it is readily accessible, simply repeated, and sufficiently sensitive for detection of most main pathologies.

\section{Factors affecting Long-Term Neurodevelopment:}

A variety of perinatal factors are proven to be associated with brain injuries and long-term neurodevelopmental outcomes in pre-term delivery. These involved GA at delivery, birth weight, multiple gestations, chorioamnionitis, antenatal corticosteroids, broncho-pulmonary dysplasia, established sepsis and/or necrotizing enterocolitis, and intra-ventricular haemorrhage, detected on cUS (defined by Volpe sorting). Well-established tri-dimensional standards based on cUS charts for assessing brain sizes and diameters revealed a considerable change in brain sizes among very pre-term babies with no brain pathology investigated at TEA and term-delivered controls are accessible, signifying a pattern of slower brain growth in very pre-term babies by TEA. Brain MRI was used in different studies for comparing with these US results supported that smaller brains on neuroimaging are usually connected to risk of neuro-developmental issues.

In the current work, we utilized our cUS standards for comparison of estimated brain dimensions among very pre-term babies with un-complicated IVH and a preceding group of very pre-term babies with no normal cUS, to study influence of un-complicated IVH on brain growth at TEA.

\section{PATIENTS AND METHODS}

The study was performed at a tertiary NICU of AlEmadi hospital, Doha, Qatar. The study was explained to parents of each baby and written consents were signed.

\section{Ethical approval:}

Al-Emadi hospital, Ethical Committee Board approved the study. Each patient enrolled in the study signed an informed consent form. This work has been carried out in accordance with The Code of Ethics of the World Medical Association (Declaration of Helsinki) for studies involving humans. 
For this study we included a prospective cohort of very pre-term infants of < 32 weeks' gestation, born between 2016 and 2019, who developed IVH (grade II and III) detected on cUS during the first week after birth 1. A historical cohort of infants of similar GA, born between 2013 and 2015, with consistently normal cUS was utilized for comparison (this cohort was the one utilized to establish the original standards). The practice implemented between these two time periods were nearly the same. Infants with grade $1 \mathrm{IVH}$ and infants with other congenital or ischemic lesions or metabolic disorders were excluded.

As a part of the routine imaging protocol, the very preterm babies were scanned during the first $72 \mathrm{~h}$, then at one, two and four weeks and then monthly thereafter until TEA.

In this study, linear measurement obtained from cUS at TEA was utilized for estimating brain volume using a mathematical model (Fig. 1). This model estimates cerebral volumes from intracranial diameters, ventricular width, and the caliber of the extra-cerebral space (ECS). Mathematical equation utilized to calculate the volume of an ellipsoid was as follows: volume $=4 / 3$ $* \pi * \mathrm{R} 1 * \mathrm{R} 2 * \mathrm{R} 3)$, assuming each of the radii (R1, $\mathrm{R} 2$, and R3) to be half of the measured intracranial diameters. We have utilized this model in pre-term infants with consistently normal scans and in term infants with normal scans to ensure that the pre-term brain is smaller at TEA compared to the newborn term brain.

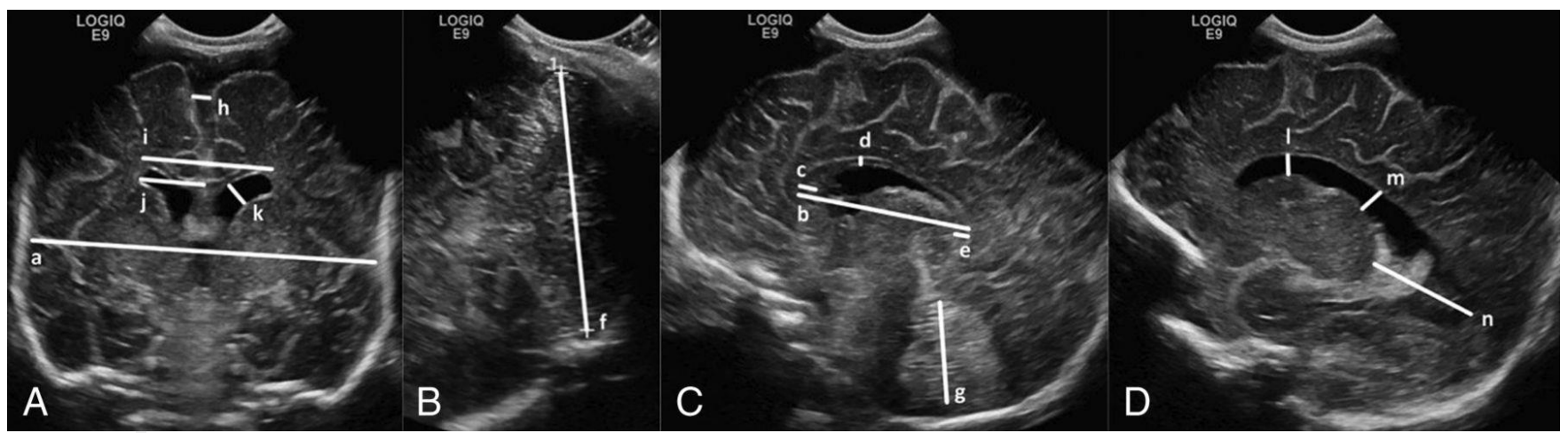

Figure (1): Cranial ultrasonography linear measures: images through the anterior fontanel in the coronal plane at the level of foramina of Monro (A) planes, and an image through the mastoid fontanel in the coronal plane posterior to the fourth ventricle (B), sagittal (C) and parasagittal (D)

Other relevant variables were collected, including prenatal steroid use, mechanical ventilation, chronic lung disorder, patent ductus arteriosus (PDA), neonatal septicemia, retinopathy of prematurity (ROP) and necrotizing enterocolitis (NEC) ${ }^{11}$.

All cUS images utilized for volume estimates were acquired at TEA by the same radiologist using a Canon Aplio i700 Scanner (PLT-704SBT 7.5 MHz and PLT-1005BT $10 \mathrm{MHz}$ ). Measurements were analyzed using Horos ${ }^{\circledR}$ software. Measurements of intracranial diameters, ventricles (Levene's ventricular index) and extra-cerebral space (ECS) were made according to the standard ranges for very pre-term and term infants (Fig. 2) ${ }^{12}{ }^{\prime} \mathbf{1 3}$.

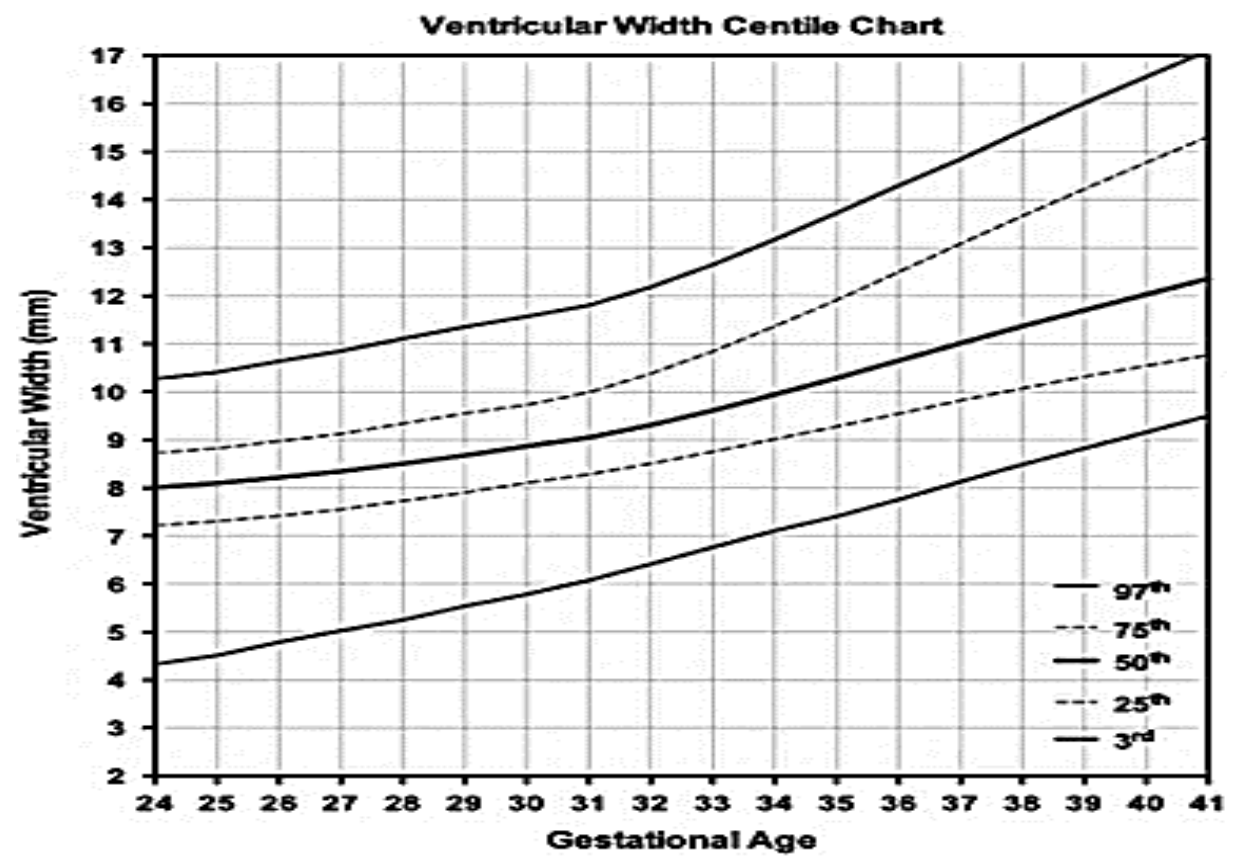

Figure (2): Centile chart of Levene's ventricular index against postmenstrual age. 


\section{Statistical analysis}

Independent samples $t$-test was used for the Statistical differences of the measured variables. A general linear model was utilized as a standard to adjust dependent variable differences on cerebral volume estimates for gestational age at birth. Babies with the normal scans group only within the GA range of the IVH group underwent a sensitivity analysis.

\section{RESULTS}

Table (1): Demographic characteristics of the studied groups (mean $\pm \mathrm{SD})$

\begin{tabular}{|l|c|c|c|}
\hline & IVH & No IVH & P-value \\
\hline $\begin{array}{l}\text { Cases } \\
\text { number }\end{array}$ & 19 & 68 & \\
\hline GA (weeks) & $\begin{array}{c}27.3 \\
( \pm 2.3)\end{array}$ & $\begin{array}{c}28.1 \\
( \pm 1.8)\end{array}$ & NS \\
\hline $\begin{array}{l}\text { Birth weight } \\
\text { (grams) }\end{array}$ & $\begin{array}{c}941 \\
( \pm 431)\end{array}$ & $\begin{array}{c}1073 \\
( \pm 274)\end{array}$ & $*<0.05$ \\
\hline $\begin{array}{l}\text { PMA at TEA } \\
\text { (wks.) }\end{array}$ & $\begin{array}{c}40.3 \\
( \pm 1.9)\end{array}$ & $\begin{array}{c}40.4 \\
( \pm 1.6)\end{array}$ & NS \\
\hline $\begin{array}{l}\text { Weight at } \\
\text { TEA (grams) }\end{array}$ & $\begin{array}{c}2852 \\
( \pm 781)\end{array}$ & $\begin{array}{c}2910 \\
( \pm 540)\end{array}$ & NS \\
\hline $\begin{array}{l}\text { Length at } \\
\text { TEA (cm) }\end{array}$ & $\begin{array}{c}45.9 \\
( \pm 3.7)\end{array}$ & $\begin{array}{c}46.9 \\
( \pm 3.3)\end{array}$ & NS \\
\hline
\end{tabular}

$*$ Values $<0.05$ is considered significant.(PMA -

Postmenstrual ages; TEA - term-equivalent ages). In this table, the babies with IVH grade-II and III had significantly low birthweight than the newborns with ordinary scan. PMA at cUS date was closely similar for the two groups. The differences between both groups in weight (2852 versus. $2910 \mathrm{~g}$ ) and length (45.9 vs 46.9 $\mathrm{cm})$ at the TEA scan were statistically insignificant.

Table (2): Relevant clinical variables for the studied groups

\begin{tabular}{|l|c|c|c|}
\hline & $\begin{array}{c}\text { IVH } \\
\mathrm{n}=19\end{array}$ & $\begin{array}{c}\text { NO } \\
\text { IVH } \\
\mathrm{n}=68\end{array}$ & P- value \\
\hline Prenatal steroids & $69 \%$ & $73 \%$ & NS \\
\hline $\begin{array}{l}\text { Mechanical } \\
\text { ventilation }\end{array}$ & $63.9 \%$ & $39 \%$ & $*<0.005$ \\
\hline $\begin{array}{l}\text { Culture-proven } \\
\text { sepsis }\end{array}$ & $34 \%$ & $19 \%$ & $*<0.05$ \\
\hline $\begin{array}{l}\text { Retinopathy of } \\
\text { prematurity(ROP) }\end{array}$ & $17 \%$ & $1 \%$ & $*<0.01$ \\
\hline $\begin{array}{l}\text { Chronic lung } \\
\text { disorder }\end{array}$ & $71 \%$ & $12 \%$ & $* *<0.001$ \\
\hline
\end{tabular}

$*$ Values $<0.05$ is considered significant. $* *$

Values $<0.001$ is considered highly significant.

In table (2), there was no statistical difference between studied groups in the rate of prenatal steroid use while group of IVH had significantly higher rates of neonatal sepsis, mechanical ventilation and ROP. The group of IVH had higher percentage of chronic lung disorders and the statistics were highly significant.

Table (3): Estimated brain measurements and diameters at TEA among the studied groups

\begin{tabular}{|l|c|c|c|}
\hline \multicolumn{1}{|c|}{ cUS variables } & $\begin{array}{c}\text { IVH } \\
\mathrm{n}=19\end{array}$ & $\begin{array}{c}\text { No IVH } \\
\mathrm{N}=68\end{array}$ & $\begin{array}{c}\mathrm{p}- \\
\text { value }\end{array}$ \\
\hline $\begin{array}{l}\text { Bi-frontal diameter } \\
(\mathrm{mm})\end{array}$ & $\begin{array}{c}69.3 \\
( \pm 0.8)\end{array}$ & $\begin{array}{c}70.1 \\
( \pm 0.5)\end{array}$ & $\mathrm{NS}$ \\
\hline $\begin{array}{l}\text { Brain tissue Bi- } \\
\text { parietal } \\
\text { diameter(mm) }\end{array}$ & $\begin{array}{c}73 \\
( \pm 2.7)\end{array}$ & $88( \pm 3.2)$ & $*<0.05$ \\
\hline $\begin{array}{l}\text { Occipito-frontal } \\
\text { diameter }(\mathrm{cm})\end{array}$ & $\begin{array}{c}10.9 \\
( \pm 0.7)\end{array}$ & $\begin{array}{c}11.3 \\
( \pm 0.6)\end{array}$ & $*<0.05$ \\
\hline $\begin{array}{l}\text { Transverse } \\
\text { cerebellar diameter } \\
(\mathrm{mm})\end{array}$ & $\begin{array}{c}51.1 \\
( \pm 1.1)\end{array}$ & $\begin{array}{c}49.9 \\
( \pm 1.3)\end{array}$ & $\mathrm{NS}$ \\
\hline $\begin{array}{l}\text { Cerebral size }\left(\mathrm{cm}^{3}\right) \\
\text { Cranial size }\left(\mathrm{cm}^{3}\right)\end{array}$ & $\begin{array}{c}338 \\
( \pm 64)\end{array}$ & $\begin{array}{c}384 \\
( \pm 45)\end{array}$ & $\mathrm{NS}$ \\
\hline $\begin{array}{l}\text { Levene's ventricular } \\
\text { index }\end{array}$ & $\begin{array}{c}13.8 \\
( \pm 2.5)\end{array}$ & $\begin{array}{c}12.3 \\
( \pm 61)\end{array}$ & NS \\
\hline $\begin{array}{l}\text { Thalamo-occipital } \\
\text { distance (mm) }\end{array}$ & $\begin{array}{c}23.7 \\
( \pm 7.9)\end{array}$ & $\begin{array}{c}21.4 \\
( \pm 3.1)\end{array}$ & $*<0.05$ \\
\hline
\end{tabular}

$*$ Values $<0.05$ is considered significant.

Table (3) showed that Levene's ventricular index At TEA was significantly higher in babies with IVH (13.8 vs $12.3 \mathrm{P}<0.05)$. In addition, occipito-frontal diameter was significantly smaller in IVH group (10.9 VS $11.3 \mathrm{~cm} P$ value $<0.05$ ) and brain tissue bi-parietal diameter was significantly smaller in IVH group (73 VS $88 \mathrm{~mm} \mathrm{P}$ value < 0.05). While, thalamo-occipital distance was larger in IVH group (23.7 VS $21.4 \mathrm{~mm} \mathrm{P}$ $<0.05)$ and there were no significance among the two groups as regards bi-frontal diameter and transverse cerebellar diameter.

Our tridimensional standards showed trending toward smaller cranial size (384 versus $\left.414 \mathrm{~cm}^{3}\right)$ and very like assessed cerebral size (338 versus $341 \mathrm{~cm}^{3}$ ) in babies with IVH and with ordinary images, but the differences remained statistically insignificant.

For more satisfactory results, we used the general linear standards to match the cranial and cerebral diameters adjusted for gestational age and the statistical differences between the two groups remained insignificant. The corrected cerebral sizes were 332 vs $346 \mathrm{~cm}^{3}$ and for cranial sizes were 409 vs $503 \mathrm{~cm}^{3}$ respectively for very preterm babies with IVH and babies with normal cUS.

\section{DISCUSSION}

Spontaneous brain hemorrhage in preterm infants typically starting in the sub-ependymal germinal matrix covering the caudated nucleus lateral to the caudo-thalamic groove and occasionally in the choroid plexus. The germinal matrix is extremely vascular tissue 
and is a source of neuro-blasts, the construction units of cerebral cortex, basal ganglia, and other constructions. It is largest at 24-32 weeks of pregnancy, then reduces, and is almost absent in the term baby ${ }^{\mathbf{1 4}, 15}$.

The dangers of neuro-developmental complications accompanying IVH per se are considerably variable ${ }^{16}$. The classic complication of IVH comprise parenchymal hemorrhagic infarction and post-hemorrhagic ventricular dilations ${ }^{2}$. With improved cUS equipment and skills, cerebral hemorrhage and white matter lesion, which significantly determine the neuro-developmental outcome, can be detected ${ }^{17}$.

Because of its greater neuro-anatomical specificity, MRI presents a high value in diagnosing and quantifying white matter injuries (WMI), early and mild IVH, cerebral malformations, and posterior fossa lesions ${ }^{18}$. MRI may as well aid in the diagnosis of inborn faults of metabolism ${ }^{19}$. WMI include cystic lesions, delayed myelination and absence or thinning of the corpus callosum ${ }^{\mathbf{2 0}}$. MRI is costly, time-consuming, and consuming method that is not always accessible. MRI in critical preterm babies is still challenging ${ }^{\mathbf{2 1}}$.

Cranial US is safe, portable, readily accessible, inexpensive, and needs no unusual preparations. In preterm babies, frontal and mastoid fontanels provide good visualizations of the white matter, ventricular system, and cerebellum. cUS is perfect for detection of germinal matrix IVH, large cerebellar hemorrhage, and echogenic areas in white matter ${ }^{22}$.

Tridimensional standards were established and permitted brain volumes estimations at TEA of pre-term babies and revealed that with no main cUS lesions, children had small sized brains at TEA when matched to term-delivered controls 9 .

In our work, the very preterm babies with IVH had lower GA and were exposed more than other group to a variety of complications as neonatal sepsis, ROP, necessity for mechanical ventilation and bronchopulmonary dysplasia. There was about one week difference between study groups in gestational age so, we applied the corrected standards to ensure the absence of significant difference in the sizes and dimensions of the brain values after applying these corrected values and the similarity between the two studied groups remained the same.

In the study, there were no considerable changes in the estimated cranial and cerebral sizes, bifrontal diameter and transverse cerebellar diameter between the group of IVH and the group with normal cUS. There were significant statistical differences between both groups in Levene ventricular index, thalamo-occipital diameter, and bi-parietal diameter. However, these values still in the acceptable ranges, also our estimated cranial and cerebral sizes were nearly matched with different studies using MRI in their work 23. This study is nearly matched with study done by Graca et $a l$. in which the difference between pre-term babies with normal cUS and those with IVH without associated pathology as regards cerebral volume, Levene ventricular index and thalamooccipital distance were statistically insignificant 9. Another study by Vasileiadis $\boldsymbol{e t}$ al. found significant decrease in the cerebral germinal matrix in IVH group. This result still significant even after exclusion of potential confusing influences and after correction of the size differences among the babies. There was no change in the sizes of sub-cortical gray matter, white matter, or cerebrospinal fluids. These results postulated that IVH led to potential glial precursor cell loss, but this theory still not confirmed ${ }^{24}$.

This study was a prospective one but in fact, we faced too many restrictions. Primarily, we did not use a contemporary group even the period among the group with normal scan and the group with IVH was short (about 3 years) and the study performed by the same investigator as well as the same scanner. Secondly, because of obtainability and ethical limitations, we were not able to accomplish MRI to additionally confirm our findings. Because of these limitations, it is recommended to follow these patients at school age to finally assess the neuro-developmental status.

\section{CONCLUSION:}

Estimated cerebral volumes based on the cUS measurements were not considerable between very preterm babies with grade II and grade III IVH and that with normal scan, also by using these data, clinician can easily decide which infants are in need for further MRI study at TEA and/ or more long term follow up program.

\section{Conflict of interest:}

The authors declare no conflict of interest.

\section{Funding source:}

The authors have no financial interest to declare in relation to the content of this article. The Article Processing Charge was paid for by the authors.

\section{REFERENCES}

1. EXPRESS group (2010). Incidence of and risk factors for neonatal morbidity after active perinatal care: extremely pre-term infants' study in Sweden (EXPRESS). Acta Pediatr., 99: 978-992

2. Woodward L, Anderson P, Austin N et al. (2006): Neonatal MRI to predict neuro-developmental outcomes in pre-term infants. N Engl J Med., 355: 685-94.

3. Plaisier A, Raets M, Ecury-Goossen G et al. (2015): Serial cranial ultrasonography or early MRI for detecting pre-term brain injury? Arch Dis Child Fetal Neonatal Ed., 100: F293-300.

4. Leijser L, de Bruïne F, van der Grond J et al. (2010): Is sequential cranial ultrasound reliable for detection of white matter injury in very pre-term infants? Neuroradiology, 52: 397-406.

5. Aptook A, O'Shea T, Shankaran S et al. (2005): Adverse neuro-developmental outcomes among extremely low birth weight infants with a normal head ultrasound: prevalence and antecedents. Paediatrics, 115: 673-80. 
6. Keunen K, Išgum I, van Kooij B et al. (2016): Brain volumes at term-equivalent age in pre-term infants: imaging biomarkers for neuro-developmental outcome through early school age. Pediatr., 172: 88-95.

7. Ferriero D (2018): MRI at term equivalent in pre-term infants: the wise choice. Pediatr. Res., 84: 791-792.

8. Gui L, Loukas S, Lazeyras F et al. (2019): Longitudinal study of neonatal brain tissue volumes in pre-term infants and their ability to predict neurodevelopmental outcome. Neuroimage, 185: 728741.

9. Graça A, Cardoso K, Costa J et al. (2013): Cerebral volume at term age: comparison between pre-term and term-born infants using cranial ultrasound. Early Hum. Dev., 89: 643-648

10. Volpe J (1989): Intraventricular hemorrhage in the premature infant? Current concepts. Part II. Ann. Neurol., 25: 109-116.

11. The International Neonatal Network (1993): The CRIB (clinical risk index for babies) score: a tool for assessing initial neonatal risk and comparing performance of neonatal intensive care units. Lancet., 342: 193-198

12. Schimmel M, Hammerman $\mathrm{C}$, Bromiker $\mathrm{R}$ et al. (2006): Third ventricle enlargement among newborn infants with trisomy 21. Pediatrics, 117: e928-e931.

13. Leijser L, Srinivasan L, Rutherford $M$ et al. (2007): Structural linear measurements in the newborn brain: accuracy of cranial ultrasound compared to MRI. Pediatr. Radiol., 37: 640-648.

14. Leijser L, de Vries L (2019): Pre-term brain injury: germinal matrix-intraventricular hemorrhage and posthemorrhagic ventricular dilatation. In: Glass H.C. DeVries L.S. Handbook of Clinical Neurology Neonatal Neurology. Elsevier, Amsterdam, Pp: 173-199.

15. Yeo K, Thomas $R$, Chow $S$ et al. (2020): Improving incidence trends of severe intraventricular hemorrhages in pre-term infants <32 weeks gestation: a cohort study. Arch. Dis. Child. Fetal Neonatal Ed., 105: F145-F150
16. Mukerji A, Shah V, Shah P (2015): Periventricular/intraventricular hemorrhage, and neurodevelopmental outcomes: a meta-analysis. Pediatrics, 136(6):1132-1143.

17. Brouwer M, de Vries $L$, Kersbergen $K$ et al. (2016): Effects of posthemorrhagic ventricular dilatation in the pre-term infant on brain volumes and white matter diffusion variables at term-equivalent age. J. Pediatr., 168: 41-49.

18. Chari A, Mallucci, C, Whitelaw A et al. (2021). Intraventricular haemorrhage and posthaemorrhagic ventricular dilatation: moving beyond CSF diversion. Childs Nerv Syst.,381:52-58.

19. Setänen S, Lehtonen L, Parkkola R et al. (2016): Prediction of neuromotor outcome in infants born preterm at 11 years of age using volumetric neonatal magnetic resonance imaging and neurological examinations. Dev. Med. Child Neurol., 58: 721-727.

20. Plaisier A, Raets M, Ecury-Goossen G et al. (2015): Serial cranial ultrasonography or early MRI for detecting pre-term brain injury? Arch Dis Child Fetal Neonatal Ed., 100 (4): F293-300.

21. Martinez-Biarge, Groenendaal M, Kersbergen $\mathrm{K}$ et al. (2016): MRI based pre-term white matter injury classification: the importance of sequential imaging in determining severity of injury. PloS One, 11: e0156245.

22. Ballardini E, Tarocco A, Baldan A et al. (2014): Universal cranial ultrasound screening in pre-term infants with gestational age 33-36 weeks. A retrospective analysis of 724 newborn. Pediatr Neurol., 51 (6): 790-4.

23. Yum S, Im S, Seo Y et al. (2019): Enlarged subarachnoid space on cranial ultrasound in pre-term infants: neuro-developmental implication. Sci. Rep., 9: 1-9.

24. George T, Vasileiadis, Neil Gelman, Victor K et al. (2004): Uncomplicated Intraventricular Hemorrhage Is Followed by Reduced Cortical Volume at Near-Term Ag. AAP; paediatrics, 114 (3): 367-372 